\title{
A Case Study of Stratospheric Ozone Affecting Ground-Level Oxidant Concentrations
}

\author{
ROBERT G. LAMB ${ }^{1}$ \\ Systems Applications, Inc., San Rafael, Calif. 94903
}

(Manuscript received 15 November 1976, in revised form 31 May 1977)

\begin{abstract}
During the predawn hours of 19 November 1972, the air pollution monitoring station at Santa Rosa, Calif., recorded five consecutive hours of oxidant concentrations in excess of the present National Ambient Air Quality Standard. The highest of the hourly averages was $0.23 \mathrm{ppm}$. From a detailed analysis of the meteorological conditions surrounding this incident, it is shown that the ozone responsible for the anomalous concentrations originated in the stratosphere and not from anthropogenic sources.
\end{abstract}

\section{Introduction}

During the predawn hours of 19 November 1972, the air pollution monitoring station at Santa Rosa, Calif., recorded five consecutive hours of oxidant concentrations in excess of the present National Ambient Air Quality Standard. (For convenience this event is referred to hereafter as the "Santa Rosa episode" or just "the episode.") The largest of the five hourly averaged concentrations was $0.23 \mathrm{ppm}$, a value three times larger than the second highest hourly oxidant level recorded in all of Northern California during the entire month of November (see Fig. 1). The magnitude of this anomaly and the fact that it occurred during a rainy night with temperatures in the low 40's prompted the Bay Area Air Pollution Control District to conclude in their Contaminant and Weather Summary for November 1972 that ". . . the probable cause (of the Santa Rosa episode) was stratospheric ozone and certainly not anthropogenic pollution." The purpose of this paper is to examine in detail the meteorological conditions surrounding this episode, so as to establish whether stratospheric ozone was indeed the cause.

\section{Three hypotheses}

Rather than focusing on a single premise, we consider all three of the hypotheses that can be advanced to explain the episode. These are 1) that the episode was merely an artifact of an instrument malfunction, 2) that it was caused by ozone of an anthropogenic origin, or 3) that ozone from natural sources, in particular the stratosphere, was responsible. We made a diligent effort to collect and analyze all currently available evidence, both supportive and contradictory

\footnotetext{
'Mailing address: Department of Chemical Engineering, California Institute of Technology, Pasadena 91125.
}

of each of these three hypotheses. This evidence, which we believe encompasses a vast majority of the significant information, is used below to test each hypothesis in turn. In the final analysis, one hypothesis emerges clearly as the valid explanation.

\section{a. Bypothesis 1: Instrument malfunction}

There are two tests that together constitute a simple yet reliable indication of whether the oxidant instrument that recorded the episode was malfunctioning at the time. The first is to examine the instrument's strip-chart record for patterns in the trace that are similar to those of previous incidents when the instrument was known to have malfunctioned. The second test is to examine the concurrent records of other instruments to determine whether their traces are correlated with that of the oxidant instrument at the time of the episode.

Reproductions of the continuous records made by the oxidant, carbon monoxide, and total hydrocarbon instruments just prior to, during and immediately after the episode are shown in Fig. 2. Also shown are 15 min samples of total suspended particulate estimated from the strip-chart record of an instrument that measures the decrease in light transmission caused by the deposition of particulate matter on a paper filter tape. Results are reported as a coefficient of haze $(\mathrm{COH})$ with one $\mathrm{COH}$ unit defined as that quantity of particles which produces an optical density of 0.01 when measured by light transmission at $400 \mathrm{~nm}$. The transmission of dust-free filter paper is taken as $100 \%$. At the Santa Rosa station an instrument manufactured by AISI is used.

It might well appear to the untrained eye that the erratic behavior of the ozone record during the episode is symptomatic of instrument failure. However, $\mathrm{Mr}$. James Sandberg of the Bay Area Air Pollution Con- 


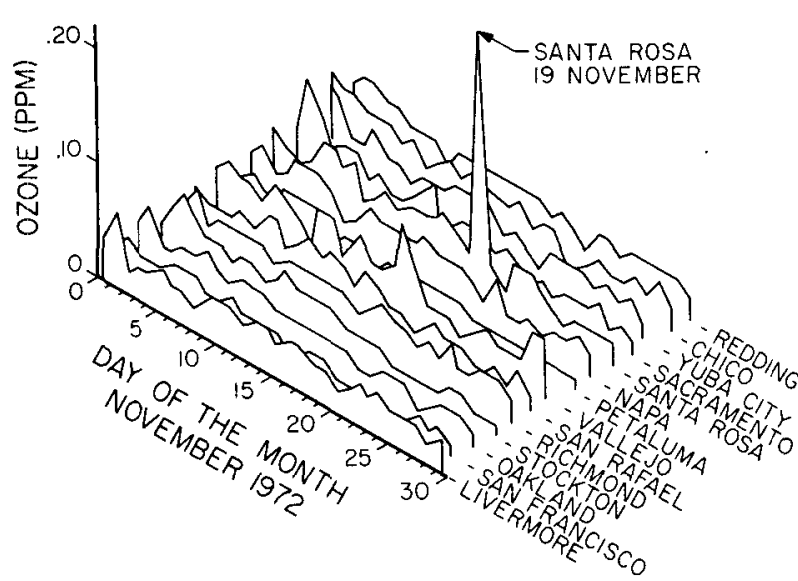

Fig. 1. Maximum hourly averaged oxidant concentration observed on each day of November 1972 at northern California monitoring stations surrounding the Santa Rosa area. (Data from California Air Resources Board, 1972.)

trol District (BAAPCD) has stated (private communication, 1976) that before the BAAPCD's comment regarding the episode was published in Contaminant and Weather Summary, several experts familiar with this particular instrument examined the trace shown in Fig. 2 and concluded that it was normal. This instrument, which is supplied by the Mast Development Company, is an amperometric or coulometric device. The measurement principle is based on the electrochemical detection of $\mathrm{I}_{3}^{-}$which is produced via oxidation $\left(\mathrm{O}_{3}\right.$ plus other oxidants $)$ of $\mathrm{I}^{-}$to $\mathrm{I}_{3}^{-}$. Since the response time of this instrument is $1 \mathrm{~min}$, even the steep slope of the trace that occurs at 0400 PST (the actual slope is exaggerated by the compressed scale of Fig. 2) is consistent with normal operating behavior.

The conclusion that the ozone instrument was not malfunctioning is supported by the behavior of the carbon monoxide, total hydrocarbon and particulate records shown in the figure. All three instruments record nearly simultaneous drops in concentrations just prior to the onset of the major rise in oxidant concentration. In all three cases, concentrations remained at levels approaching background values until after the maximum oxidant concentration had passed. These results point strongly to some atmospheric phenomenon, rather than failure of the oxidant instrument, as the cause of the episode. Unfortunately, the wind instruments at the Santa Rosa monitoring station were down for maintenance during the episode so it is not possible to correlate wind data with the oxidant measurements. It will be shown later, however, that certain meteorological parameters observed a short distance from the station are correlated with the records shown in Fig. 2.

In conclusion, there is no evidence to support the premise that instrument failure was responsible for the Santa Rosa episode data.

\section{b. Hypothesis 2: Anthropogenic ozone}

The fact that the episode occurred during the night precludes the possibility that photochemical processes acting on local pollutant emissions produced the oxidant during the time the episode was in progress. Rather, if anthropogenic sources were responsible, the oxidant was generated the previous day and transported into the Santa Rosa area by atmospheric circulation.

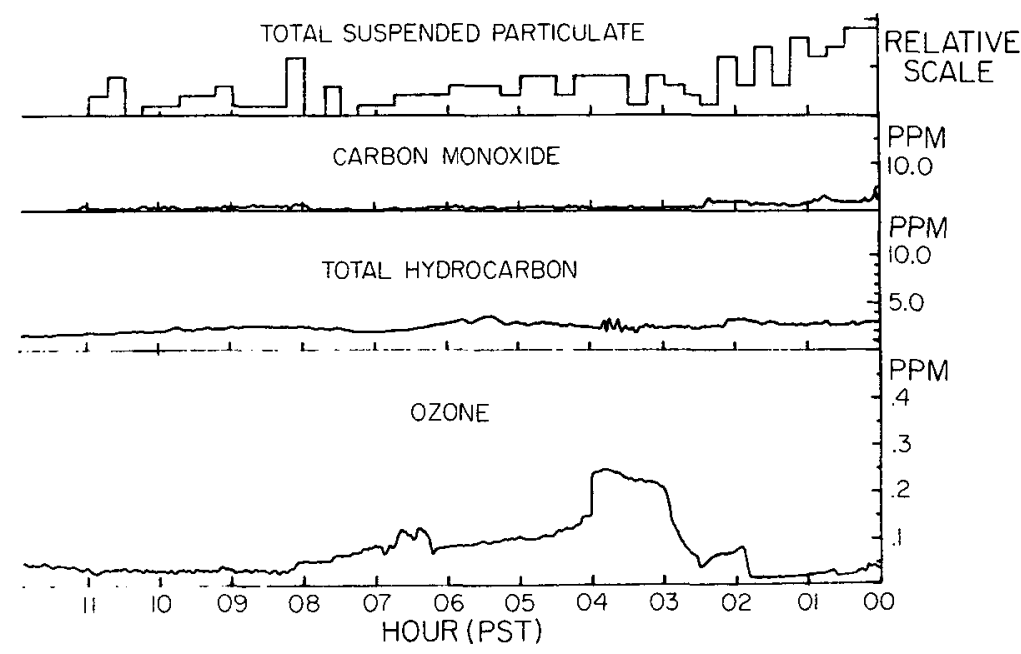

FIG. 2. Reproductions of the strip-chart records of the oxidant, hydrocarbon and carbon monoxide instruments of the Santa Rosa Air Quality Monitoring Station for 19 November 1972. Total suspended particulate values have been estimated from the strip-chart record of an automatic particulate sampling instrument (see text). 
TABLE 1. Surface weather observations at the Santa Rosa Airport on 18 November 1972 (the day prior to the episode).

\begin{tabular}{|c|c|c|c|c|c|c|}
\hline $\begin{array}{l}\text { Hour } \\
\text { (PST) }\end{array}$ & $\begin{array}{l}\text { Sky cover } \\
\text { (tenths) }\end{array}$ & $\begin{array}{l}\text { Visibility } \\
\text { (mi) }\end{array}$ & Weather & $\begin{array}{c}\text { Temper- } \\
\text { ature } \\
\left({ }^{\circ} \mathrm{F}\right)\end{array}$ & $\begin{array}{l}\text { Wind } \\
\text { Direction }\end{array}$ & $\begin{array}{c}\text { Speed } \\
(\mathrm{kt})\end{array}$ \\
\hline 0700 & 10 & $\frac{1}{2}$ & Very light rain, and fog & 44 & - & 0 \\
\hline 0800 & 10 & 1 & Very light rain, and fog & 45 & - & 0 \\
\hline 0900 & 10 & 6 & Very light rain, and fog & 47 & SSW & 4 \\
\hline 1000 & 10 & 6 & Fog, smoke and haze & 51 & $\mathrm{SE}$ & 8 \\
\hline 1100 & 10 & 6 & Fog, smoke and haze & 48 & NNW & 12 \\
\hline 1200 & 10 & 10 & & 54 & $\mathbf{N}$ & 6 \\
\hline 1300 & $6-9$ & $30+$ & & 55 & NNW & 7 \\
\hline 1400 & $6-9$ & $30+$ & & 58 & NNW & 13 \\
\hline 1500 & $1-5$ & $30+$ & & 58 & NNW & 12 \\
\hline 1600 & $1-5$ & $30+$ & & 55 & NNW & 10 \\
\hline 1700 & $1-5$ & $30+$ & & 51 & $\mathrm{~W}$ & 7 \\
\hline 1800 & $1-5$ & 15 & & 47 & WSW & 7 \\
\hline 1900 & $1-5$ & 15 & & 46 & $\mathrm{~W}$ & 4 \\
\hline 2000 & 10 & 15 & & 44 & NE & 5 \\
\hline 2100 & 10 & 15 & & 41 & $\mathrm{SE}$ & 5 \\
\hline 2200 & 10 & 15 & & 43 & $\mathrm{E}$ & 3 \\
\hline 2300 & 10 & 15 & & 40 & NNW & 3 \\
\hline
\end{tabular}

Santa Rosa is situated about $30 \mathrm{mi}$ north-northwest of the northern edge of the San Francisco Bay Area metropolitan district and is subject, under certain meteorological conditions, to invasions of contaminated air from the Bay region.
On the day preceding the episode, weather conditions in the San Francisco area were cloudy, rainy and cold during the morning hours but there was a partial clearing in the afternoon as a front moved through. Prior to the frontal passage, surface winds

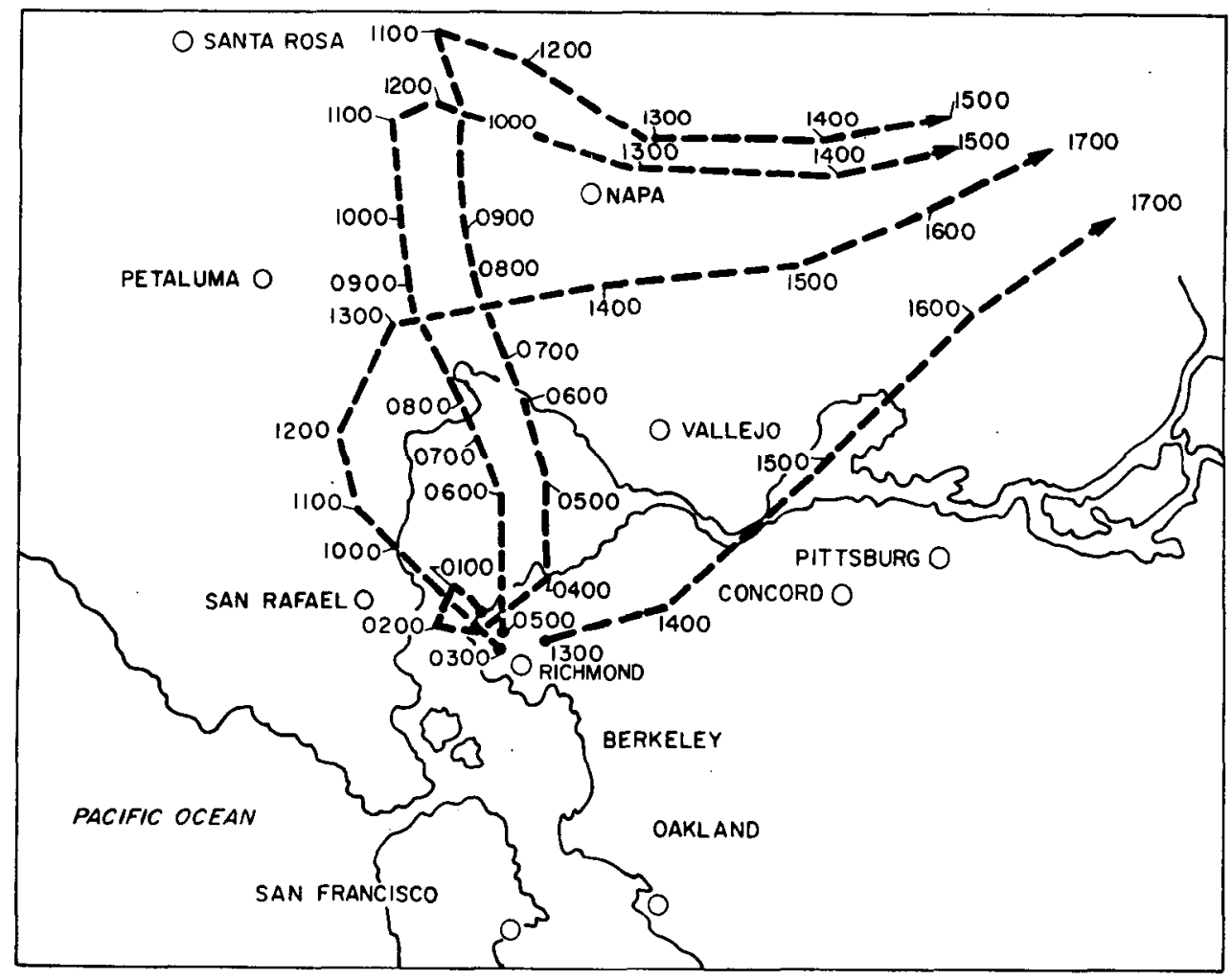

FIG. 3. Computed surface level trajectories for air parcels leaving the Richmond area at 0000, 0500, 0900 and 1300 PST on 18 November 1972, the day preceding the episode. Numbers along the trajectories denote arrival times (PST). Circles represent the sites from which wind data were available. 


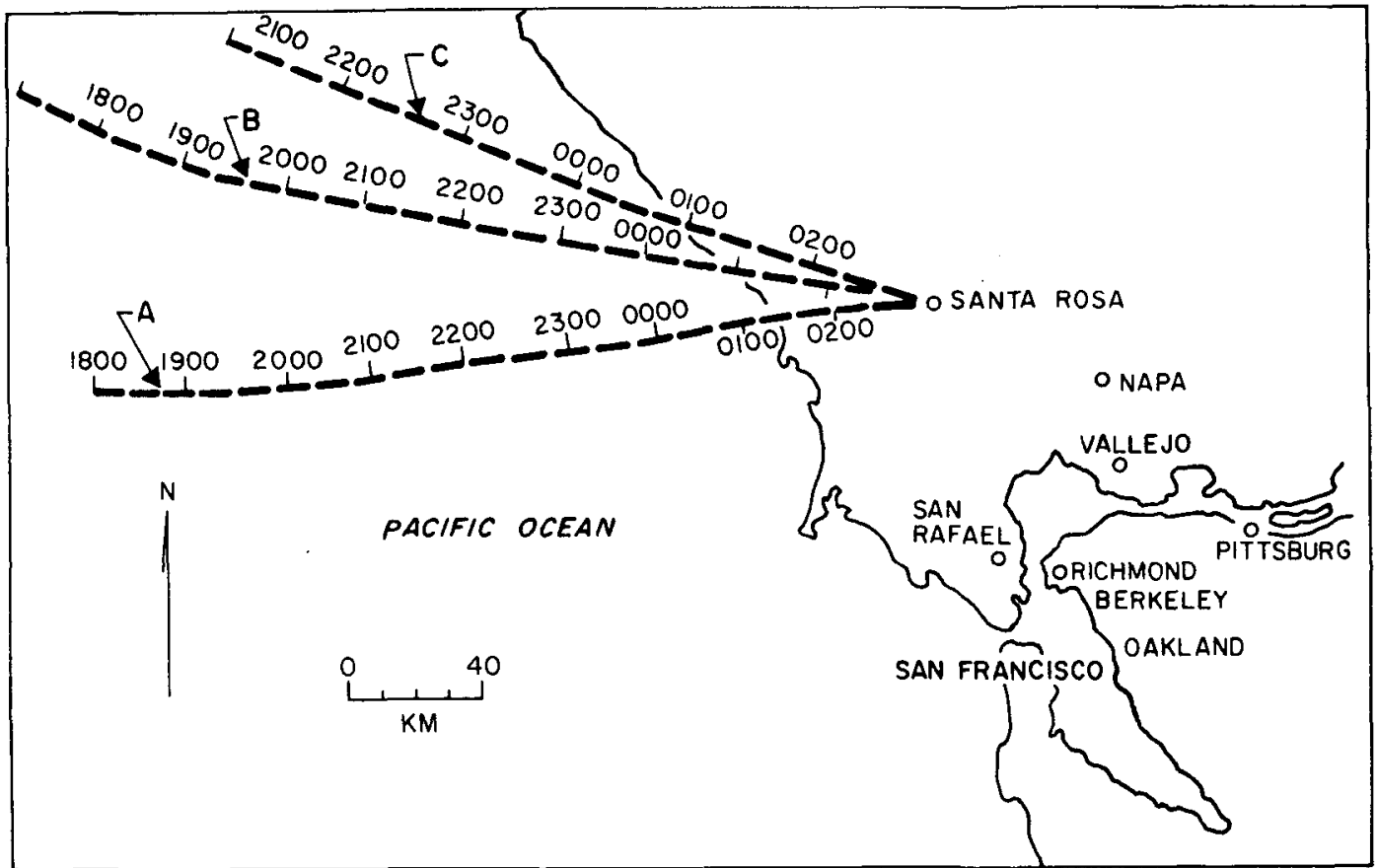

FIG. 4. Computed trajectories of air parcels arriving at Santa Rosa at the time of the episode, 0300 PST 19 November 1972, at different elevations. $A=925 \mathrm{mb}, B=825 \mathrm{mb}, C=725 \mathrm{mb}$. Numbers along each trajectory denote time (PST).

were generally from the south so there was a chance that photochemical pollutants produced from hydrocarbon and $\mathrm{NO}_{x}$ emissions in the Bay Area could have reached Santa Rosa. Table 1 shows the surface weather observation recorded at the Santa Rosa airport on 18 November 1972. The cloud cover, visibility, weather and temperature data shown are typical of the conditions recorded at all stations in the San Francisco region on that day.

Estimates of sunlight intensities, atmospheric stability, mixing depth and wind speed and direction were derived from the weather records of nine stations in the Santa Rosa-San Francisco area and the upper air soundings made twice daily at the Oakland airport. These data were then used as inputs in a computer simulation model of photochemical smog to determine whether ozone in the concentrations observed in the episode could have been produced by Bay Area emissions and transported into the Santa Rosa area. The trajectories shown in Fig. 3 are those estimated from surface wind observations recorded at the sites indicated by circles. These trajectories represent the simulated paths of air parcels leaving the Richmond area at different hours on 18 November. Richmond was chosen as the starting point of these trajectories partly because there are considerable hydrocarbon emissions from this area and partly because air parcels originating at more southerly locations in the Bay Area would have had to pass near Richmond in order to arrive at Santa Rosa by the shortest and hence least dispersive route.
The earliest starting time of the four trajectories shown in Fig. 3 is $0000^{2}$ on 18 November, i.e., about $27 \mathrm{~h}$ prior to the episode. The last release time is 1300 . As the figure shows, none of the air passing Richmond on the 18th was able to reach Santa Rosa. In fact, the northern limit of the progress of air trajectories was probably less than that shown because there was a strong wind direction shear in the mixed layer during that day, not accounted for in the simulation, which would have caused pollutants that managed to reach the upper levels of the mixed layer to be blown back toward the southeast. Only a relatively shallow layer of air next to the ground was moving in the manner implicit in the trajectories shown in Fig. 3.

The rapid change in the trajectories that occurs near midday is due to the passage of the front mentioned earlier. The effects of the front are also clearly evident in the surface weather at Santa Rosa (shown in Table 1). The sudden change in wind speed and direction at 1100 marks the time of the front's passage, and the subsequent increase in visibility marks the replacement of the rather stagnant air that had covered the city during the morning hours by the new air mass behind the front. This last point is significant because it indicates that the old air mass, contaminated or not, that was present over Santa Rosa on the 18th was no longer around on the early morning

${ }^{2}$ Unless indicated otherwise, all times are Pacific Standard (PST). 
of the 19th. This is corroborated by the trajectory simulations of upper level air parcels shown in Fig. 4.

The trajectory marked A represents the mean path of air that arrived over Santa Rosa at 0300 on 19 November, the approximate time of the episode, at an altitude of $925 \mathrm{mb}$. This level is in the lower portion of the mixed layer behind the front. The trajectory marked $B$ represents the path of air at $825 \mathrm{mb}$, the upper part of the postfrontal mixed layer, and the trajectory labeled $C$ describes air motions at $725 \mathrm{mb}$, an altitude above the mixed layer. Thus, air present over Santa Rosa at the time of the episode had just been over the Pacific Ocean.

It is worth noting that if the trajectories shown in Fig. 4 are rotated about $30^{\circ}$ counterclockwise, the resulting pattern describes the trajectories arriving over Santa Rosa prior to the frontal passage. A comparison of these trajectories with the prefrontal portions of the surface trajectories shown in Fig. 3, i.e., the trajectory segments between the release time and 1200, emphasizes the point made earlier that only a shallow layer of air next to the ground was moving in a south to north direction.

The results of the computer simulation of ozone concentrations that accompanied the trajectory calculations are shown in Fig. 5a. The computer model on which these results are based employs a complex chemical kinetics scheme developed to describe the major processes that occur in the formation of photochemical air pollution. [The reader is referred to Hecht et al. (1974) for a detailed description.] The major objective of the ozone simulation was to de-
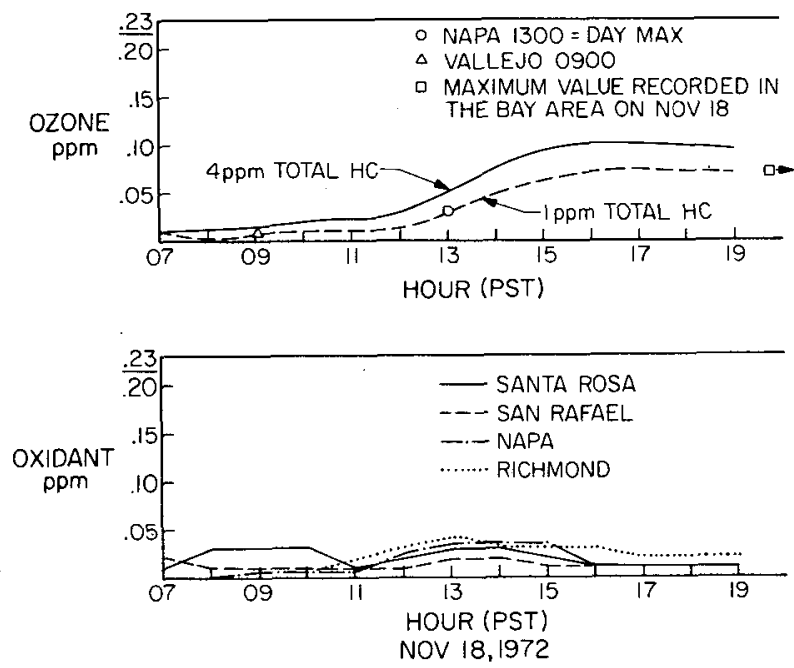

Frg. 5a. Maximum (solid line) and minimum (dashed line) ozone concentrations predicted for 18 November 1972. Oxidant observations made at monitoring stations along the trajectory leaving Richmond at 0500 (see Fig. 3) are denoted by the circle and triangle. The maximum oxidant level observed in this area is represented by the square.

Frg. 5b. Observed hourly averaged oxidant concentration at four stations in the Santa Rosa area on 18 November 1972. termine whether concentrations of the magnitude observed in the episode could have been produced from the hydrocarbon and $\mathrm{NO}_{x}$ emissions of $18 \mathrm{No}$ vember under the meteorological conditions that were prevalent that day. Due to the nonlinear character of air pollution chemistry, it was necessary to examine a range of initial hydrocarbon and $\mathrm{NO}_{x}$ concentrations to be sure that the maximum possible ozone level was detected by the model calculations. Various combinations of the maximum hydrocarbon and $\mathrm{NO}_{x}$ concentrations observed anywhere in the Bay Area during the daylight hours of the 18th $[4 \mathrm{ppm}$ total hydrocarbon (THC) and $\left.0.09 \mathrm{ppm} \mathrm{NO}_{2}\right]$ and the minimum values of these species observed ( $1 \mathrm{ppm}$ THC and $0.04 \mathrm{ppm} \mathrm{NO}_{2}$ ) were used as initial mixtures at 0700 in the numerical simulation. The breakdown of total hydrocarbon into reactive and unreactive constituents was as follows:

$$
4 \mathrm{ppm} \text { THC }\left\{\begin{array}{c}
\sim 3.2 \text { unreactive } \\
0.08 \text { olefins } \\
0.5 \text { paraffins } \\
0.1 \text { aldehydes } \\
0.1 \text { aromatics }
\end{array}\right.
$$

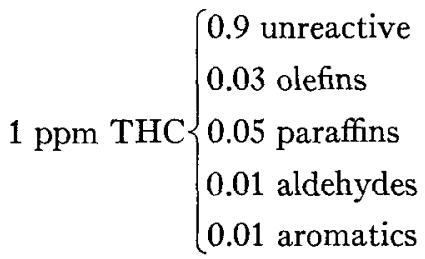

This decomposition is based on gas chromatograph studies of the composition of Los Angeles smog reported by the Scott Laboratories (1970). In the absence of measurements of the vertical distribution of pollutant concentrations, the common practice of approximating the vertical profile was used; see, e.g., Lamb and Neiburger (1971) or Reynolds et al. (1973). In the present instance, the initial concentrations of all species were assumed to be constant up to an altitude of $150 \mathrm{~m}$, roughly the height of the nocturnal inversion, and to drop off linearly to background concentration at $300 \mathrm{~m}$.

The ozone concentration predicted by these simulations ranged between the values delineated by the solid and the dashed curves shown in Fig. 5a. To facilitate a comparison of the predicted concentrations with the maximum oxidant level observed in the episode, the maximum ozone concentration included in the ordinates of Figs. $5 \mathrm{a}$ and $5 \mathrm{~b}$ has been set at the latter value, viz., $0.23 \mathrm{ppm}$. Also shown are oxidant values recorded at Napa and at Vallejo at the times that the trajectory originating at Richmond at 0500 passed near these stations (see Fig. 3).

The major assumptions inherent in the model that produced the results shown in Fig. 5a would tend to 
cause the predicted values to be too large. For example, the simulation ignored wind shear effects, which would have diluted the pollutants; full sun was assumed in the afternoon, when in fact clouds were present which would have attenuated sunlight and hence lessened the rate of ozone formation; and $\mathrm{THC}$ and $\mathrm{NO}_{x}$ concentrations larger than those observed at any single point were used as initial conditions. Despite these amplifying effects, the computed ozone concentrations fall far short of the oxidant levels observed during the episode. This result indicates that even if air from the Bay Area had been able to reach Santa Rosa, it would have caused oxidant levels no higher than $0.1 \mathrm{ppm}$. In actuality, oxidant levels were near the background values at Santa Rosa and neighboring cities on the 18th (see Fig. 5b) and the maximum value recorded anywhere in the region was $0.07 \mathrm{ppm}$ at Vallejo at 2300.

The oxidant monitoring data presented in Fig. 1 also tend to absolve urban pollution as the cause of the Santa Rosa episode, because the second, third and fourth highest levels observed in northern California during the month of November were clustered tightly around $0.08 \mathrm{ppm}$, whereas the episode value was three times larger than this.

One might also argue that through the process of long-range transport, anthropogenic ozone could have arrived at Santa Rosa from an urban area other than the San Francisco region. The synoptic-scale meteorological conditions in existence prior to the episode make this possibility highly unlikely, since the flow patterns shown in Fig. 6, to be discussed later, indicate that for at least a day prior to its arrival in Santa Rosa, the air mass in question had been over the open sea.

In conclusion, all of the evidence examined is contradictory rather than supportive of the premise that anthropogenic ozone was responsible for the Santa Rosa episode.

\section{c. Hypothesis 3: Stratospheric ozone}

The existence of evidence contradictory of the two hypotheses above is itself supportive of this last hypothesis, but of course strong, corroborative evidence is also required to make the case complete and convincing. Such evidence will be presented here.

Reed (1955) and Staley (1960) were the first to show" that during high-level cyclogenesis, stratospheric air is often injected into the troposphere. This finding was later confirmed by many observational studies (see, e.g., Danielsen, 1975). That upper level cyclogenesis occurred prior to the time of the Santa Rosa episode is evident in Figs. 6a-6c. The first of these describes the surface and upper level synoptic situations at 0400 PST 19 November 1972, about $1 \mathrm{~h}$ after the episode had begun. At this time there was a cold low at the $500 \mathrm{mb}$ level over the Oregon-
Washington border. The data for 18 and 17 November (Figs. 6b and 6c) show that this low was produced in a cyclogenetic event off the south coast of Alaska on 17 November. The rapid cooling of the air near the center of the low and the warming of the air on its southwest flank, which occur between the map times of 18 and 19 November (Figs. 6b and 6a), mark zones of ascending and descending air, respectively. This vertical flow pattern is consistent with the circulations observed by Reed (1955) and Staley (1960) in studies of cyclogenesis.

Isentropic trajectory analysis techniques such as those described by Danielsen (1961) are useful in tracing the paths of air parcels that descend dry adiabatically from the lower stratosphere into the troposphere. These techniques have been used extensively in studies of radioactive fallout (see, e.g., Reiter, 1963, and Reiter and Mahlman, 1965a).

Fig. 7a is a north-south vertical cross section of the isentropic structure of the atmosphere over the west coast of the United States between northern Washington and southern California at 0400 on 18 November-the same time as the maps shown in Fig. 6b; Fig. $7 \mathrm{~b}$ is a cross section along the same line $12 \mathrm{~h}$ later. One striking feature of these data is the rapid change that occurs in the heights and slopes of the isentropic surfaces between 26 and $30^{\circ} \mathrm{C}$. For convenience these two bounding isentropes are highlighted in the figure by dots superimposed on the curves. Between the hours of 0400 and 1600 on the $18 \mathrm{th}$, the isentropic surfaces between 26 and $30^{\circ} \mathrm{C}$ rise $100 \mathrm{mb}$ or more over Salem and descend about $50 \mathrm{mb}$ over the Oakland-Santa Rosa area. These changes reflect ascending air motions immediately ahead of the low discussed earlier (see Figs. 6a and 6b) and a descending circulation on the low's southern flank. As a result of these motions, by 1600 PST 18 November, just $11 \mathrm{~h}$ prior to the episode, air in the lower troposphere over the Santa Rosa area was part of the same isentropic surface as that of air in the lower stratosphere over northern Oregon.

This connection is clearer in the isothermal analysis shown in Fig. 8. Here the heavy lines mark the tropopause and a frontal zone, or folded tropopause as it is sometimes called. It is along frontal zones such as this that Reed (1955), Staley (1960) and others showed that air can be extracted from the lower stratosphere and injected downward into the lower troposphere.

To check whether air was descending along the frontal surfaces shown in Fig. 8, vertical velocities were computed at 1600 of the 18 th on the $28^{\circ} \mathrm{C}$ isentropic surface, i.e., roughly at the center of the portion of the frontal zone between Oakland and Medford, Ore. The results, which were obtained from the differences of height of the beginning and end points of isentropic trajectories [computed by the method 


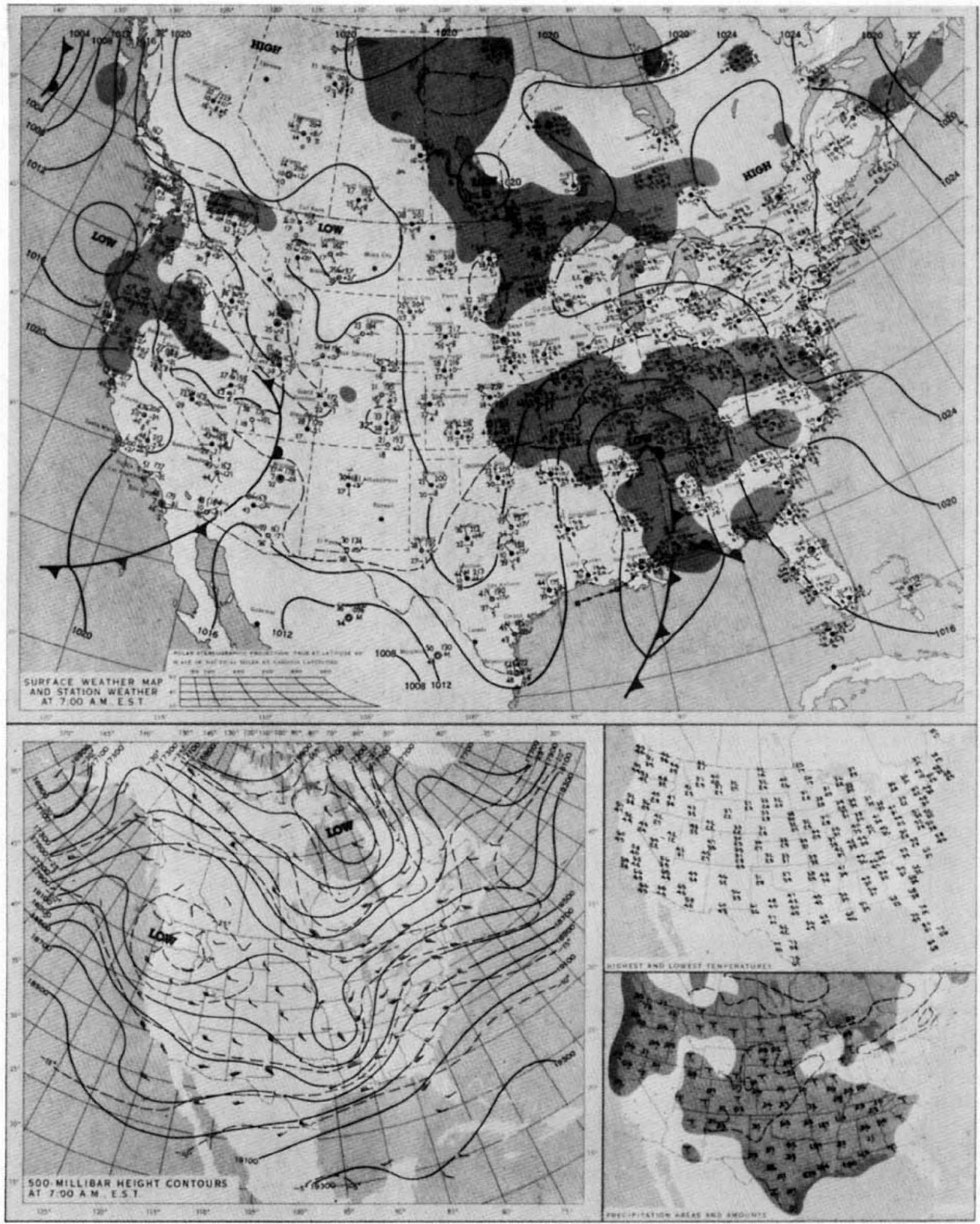

Frg. 6a. Surface and $500 \mathrm{mb}$ weather map for 0400 PST 19 November 1972. 

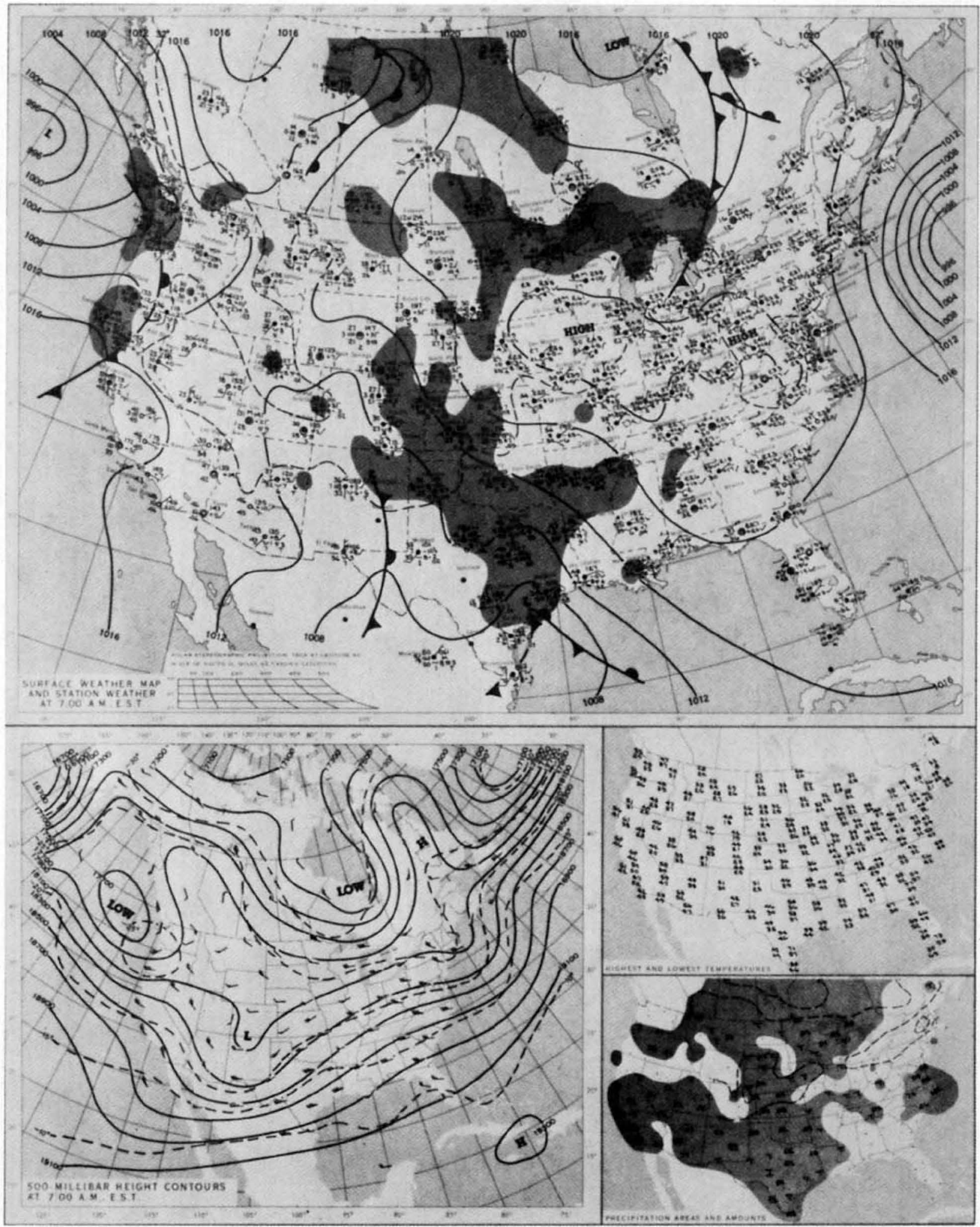

FIG. 6b. Surface and $500 \mathrm{mb}$ weather map for 0400 PST 18 November 1972. 


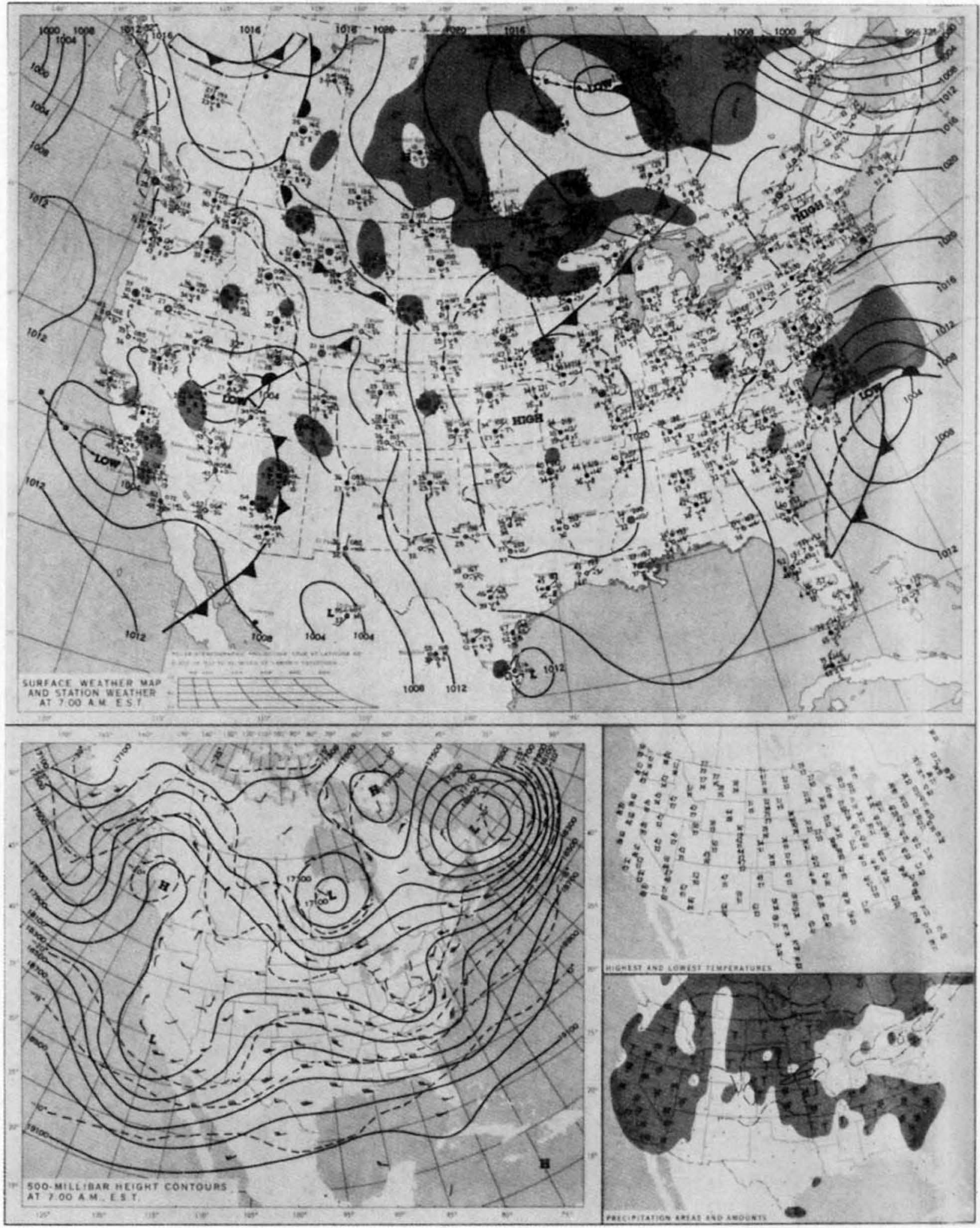

FIG. 6c. Surface and $500 \mathrm{mb}$ weather map for 0400 PST 17 November 1972. 

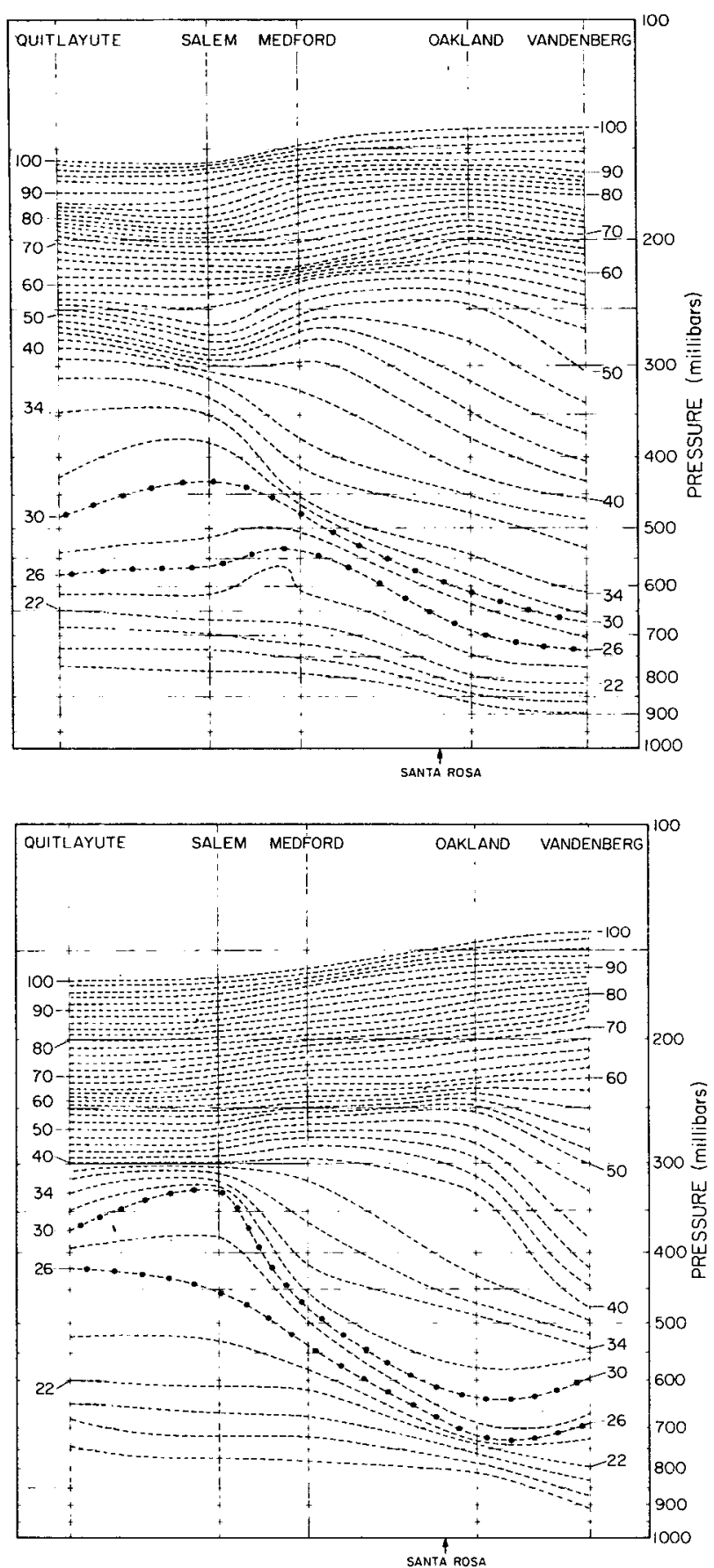

Fig. 7. Vertical cross section of the isentropic structure of the atmosphere along a north-south line between Quitlayute, Wash., and Vandenberg AFB, Calif., on 18 November 1972 at (a) 0400 PST and (b) 1600 PST. The latter is approximately $11 \mathrm{~h}$ prior to the episode. Isentropes (dashed lines) are labeled in degrees Celsius.

of Danielsen (1961)], are shown in Fig. 9. (Since upper air data are not available over the Pacific Ocean, some extrapolation of the available data was necessary to obtain vertical velocity estimates.) Sink- ing motions are apparent over all portions of the frontal zone that might influence the Santa Rosa area.

Thus, it appears that an intrusion of stratospheric air occurred over the northeastern Pacific Ocean just before the episode, but it remains to be determined whether stratospheric air managed to reach the Santa Rosa area. The customary procedure of tracing the paths of air parcels by isentropic trajectory analyses cannot be applied with acceptable accuracy in the present instance because the flow reaching Santa Rosa at the time in question had come from an area of the Pacific Ocean that is completely void of upper air data. Consequently, it is possible only to determine whether air with stratospheric characteristics was present at the area and time of interest.

Two such characteristics which are readily derivable from available data are low water vapor mixing ratio and high potential vorticity. The latter is a hydrodynamic quantity defined by

$$
P=-\frac{\partial \theta}{\partial p}\left(\zeta_{\theta}+f\right)
$$

where $\theta$ is potential temperature, $p$ atmospheric pressure, $\zeta_{\theta}$ the relative vorticity in isentropic coordinates and $f$ the Coriolis parameter. Potential vorticity has been used as a "tracer" of stratospheric air in many previous studies of stratospheric intrusion (Staley, 1960; Danielsen, 1968; Danielsen et al., 1970). The

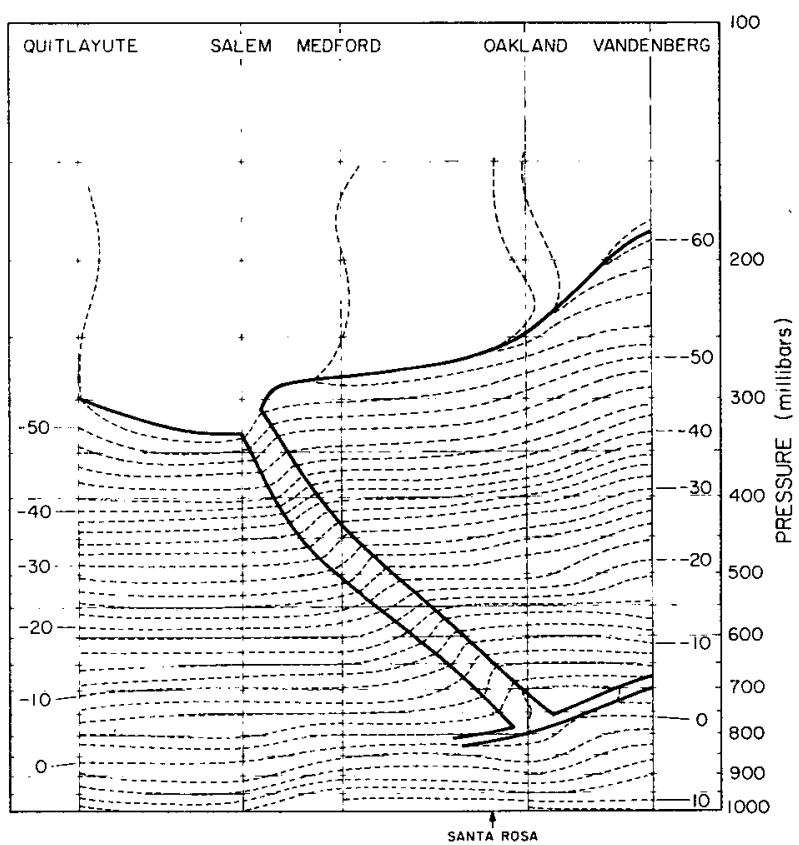

FIG. 8. Vertical cross sections of the thermal structure of the atmosphere along the north-south line between Quitlayute, Wash., and Vandenberg AFB, Calif., on 18 November 1972, approximately $11 \mathrm{~h}$ prior to the episode. Dashed lines represent isotherms (labeled in degrees Celsius); heavy solid lines denote the tropopause and frontal zone boundaries. 


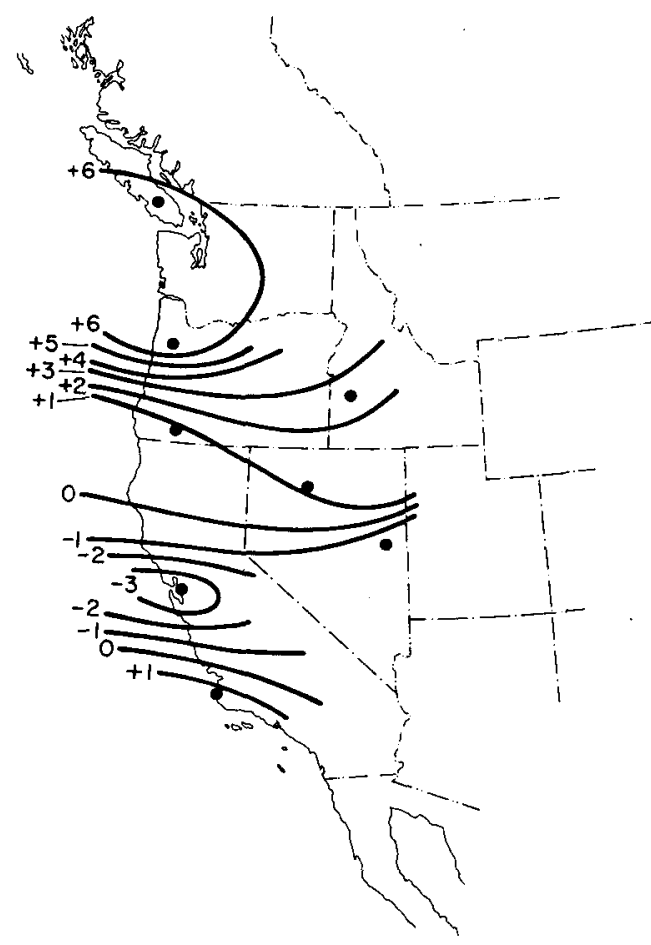

FIG. 9. Vertical velocities $\left(\mathrm{cm} \mathrm{s}^{-1}\right)$ on the $28^{\circ} \mathrm{C}$ isentropic surface at 1600 PST 18 November 1972, approximately $11 \mathrm{~h}$ prior to the episode. Dark circles mark the locations of the upper air weather stations whose data were used in these calculations.

potential vorticity of stratospheric air is generally much larger than that characteristic of the troposphere (Danielsen, 1959, 1968); and since this quantity is conserved during dry, adiabatic descent, potential vorticity is a convenient tracer of intruding stratospheric air.

Fig. 10 shows the vertical distributions of water vapor mixing ratio and potential vorticity over Santa Rosa at 1600 PST 18 November. The potential vorticity profile was calculated using Eq. (1) and $\zeta_{\theta}$ values estimated from hand-analyzed wind fields plotted on isentropic surfaces spaced at $4^{\circ} \mathrm{C}$ intervals and ranging from the $\theta=16^{\circ} \mathrm{C}$ surface, which was near ground level, up to the $\theta=64^{\circ} \mathrm{C}$ surface, which was located near the tropopause. Upper air data from the eight stations denoted by dark circles in Fig. 9 were used in these calculations. It is evident from a comparison of these results with Fig. 8 that air possessing properties characteristic of stratospheric air was present in the lower part of the frontal zone above Santa Rosa. Twelve hours later, the effects of the stratospheric intrusion are still evident in the moisture, potential temperature and wind field cross sections shown in Fig. 11. The downward protruding tongue of dry air (accentuated in the figure by the shading of the moist areas), the pattern of the isentropic surfaces, and the position of the jet stream relative to the tropopause and isentropes displayed in Fig. 11 conform exactly to the model of stratospheric intrusion proposed by Reiter (1966) on the basis of studies of radioactive fallout.

From the observations presented above, there seems little doubt that stratospheric air was present somewhere between the 600 and $800 \mathrm{mb}$ levels over Santa Rosa at the time of the episode. It remains to be established that a mechanism capable of having transported this air to the ground was present.

Information pertinent to this question is contained in the Oakland temperature and dew point soundings shown in Fig. 12. These data indicate that between 1600 PST 18 November and 0400 PST 19 November, the boundary layer cooled and the dew point temperature rose sufficiently that by the time of the episode, the lowest kilometer of air over the Santa Rosa area was conditionally unstable. A kinetic energy analysis of the 0400 sounding shows that at this hour air parcels displaced from the surface could have penetrated to an altitude of about $650 \mathrm{mb}$. Thus; it is possible that perturbations induced in the flow by the mountains lying west and northwest of Santa Rosa could have initiated cumulus clouds with tops as high as $650 \mathrm{mb}$. Since temperatures at this level were well below freezing at the time, shower activity was possible (see Mason, 1962).

This scenario is supported by the hourly rainfall

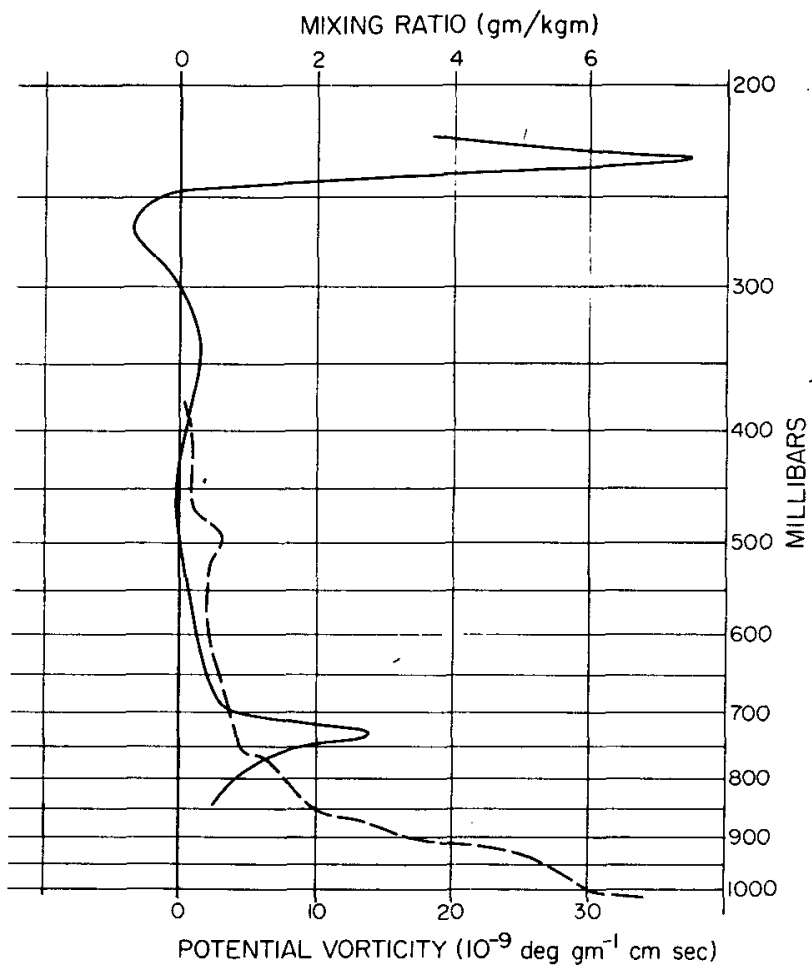

FIG. 10. Profiles of water vapor mixing ratio (dashed) and potential vorticity (solid) over Santa Rosa at 1600 PST on 18 November 1972, approximately $11 \mathrm{~h}$ prior to the episode. 
data for 19 November shown in Fig. 13. Shower activity commenced just north of Santa Rosa about one hour before the episode and progressed southward, reaching the Oakland-San Francisco area by about 0900. None of the showers recorded during this period was associated with thunderstorms and no lightning was reported. It is evident from a comparison of Fig. 13 with the oxidant record shown in Fig. 2 that the episode occurred almost simultaneously with the passage of the band of showers over the Santa Rosa area. This can be seen in more detail in Fig. 14 in which the ozone record of Fig. 2 has been displayed beside a reproduction of the strip-chart record of the raingage located at the Oakville $4 \mathrm{SW}$ site, about $9 \mathrm{mi}$ southeast of Santa Rosa.

In interpreting these data it should be kept in mind that since the band of showers was moving from north to south, rainfall would have begun at Santa Rosa before it was first observed at the Oakville site.

Thus the anomalous oxidant concentrations observed at Santa Rosa in the early morning of 19 November 1972 coincided with a brief shower of moderate to heavy intensity. This fact and the evidence presented earlier suggest that the clouds that produced this shower had just penetrated the layer of stratospheric air (lying somewhere between 600 and $800 \mathrm{mb}$ ) by the time they reached Santa Rosa, and that the down-

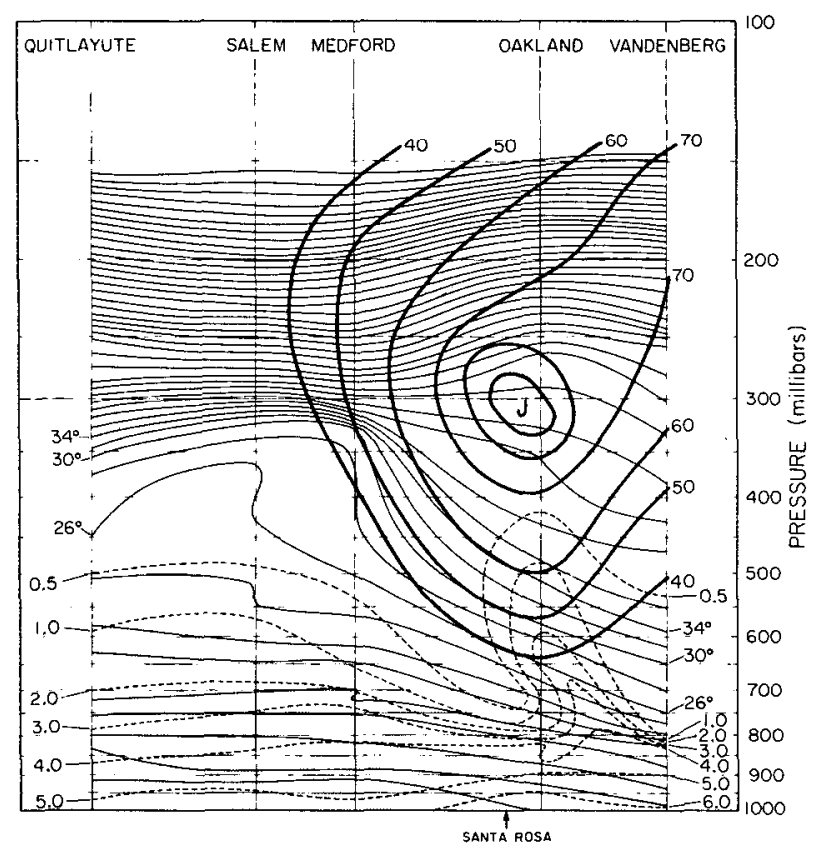

FIG. 11. Water vapor mixing ratio (dashed), isentropes (thin solid) and isotachs (heavy solid) in the Quitlayute-Vandenberg vertical cross section at 0400 PST 19 November 1972, approximately $1 \mathrm{~h}$ after the episode. Moist areas (mixing ratios larger than $1 \mathrm{~g} \mathrm{~kg}^{-1}$ ) are shaded; the core of the jet stream is denoted by the letter $\mathrm{J}$. [Units: mixing ratio, $\mathrm{g} \mathrm{kg}^{-1}$; isentropes, ${ }^{\circ} \mathrm{C}$; wind speed, kt.]

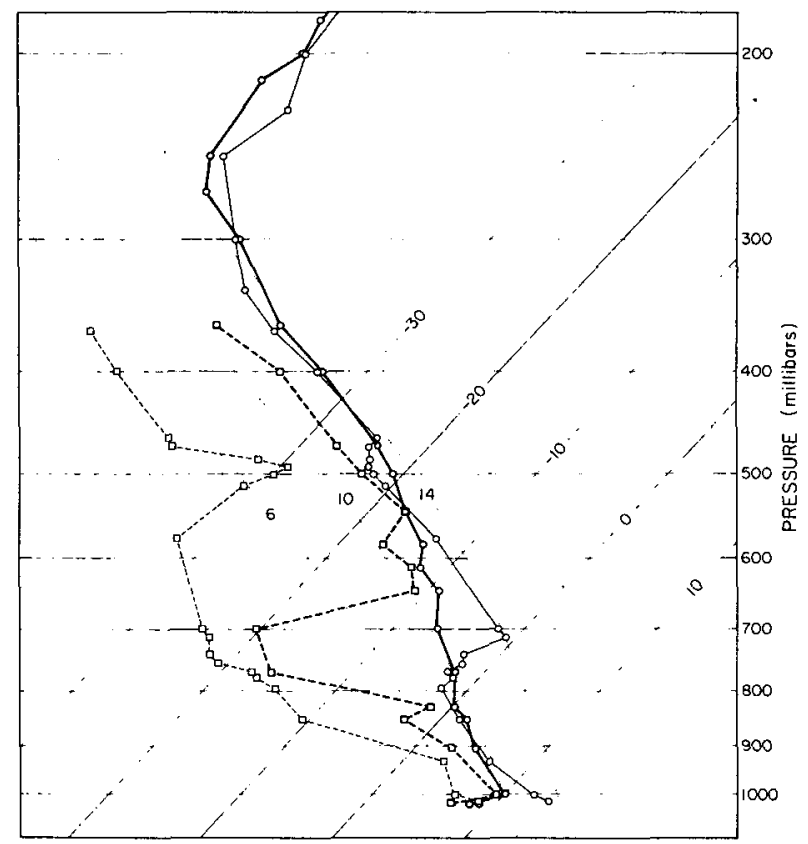

FIG. 12. Temperature (solid) and dew point (dashed) soundings at Oakland, Calif., for 1600 PST 18 November (thin lines) and 0400 PST 19 November 1972 (heavy lines). Dotted lines are saturation adiabats and sloping lines are isotherms, all labeled in degrees Celsius.

draft circulation system of the clouds carried stratospheric air and ozone to the ground.

Surface weather observations made at the Santa Rosa airport beginning at 0655 on 19 November show that between this hour and 1000 , winds were calm and that patchy ground fog was present in all directions. Calm conditions were probably present also at the time of the shower. Had the rain fallen into a less stagnant air mass, the magnitude and duration of the episode would most likely have been much smaller than they actually were.

Our conclusion that the stratospheric ozone was transported to the ground in precipitation-driven downdrafts raises the question of why oxidant anomalies were not observed at any of the other monitoring stations that reported precipitation. There is insufficient evidence to provide a conclusive answer to this question; but based on the information that is available, we offer the following explanation.

Descriptions such as that given in Byers (1959, p. 461) of the circulation regime within precipitating, cumulus clouds indicate that the downdraft originates primarily near the top of the cloud. This suggests that at the moment the top of a growing, precipitating cloud entered a layer of ozone-rich air aloft, the entire cross-sectional area of the downdraft would become contaminated with ozone. During its subsequent descent to the ground, ozone near the edges of the downdraft would become diluted by the entrainment of ozone-free air from the environment, but ozone in the 


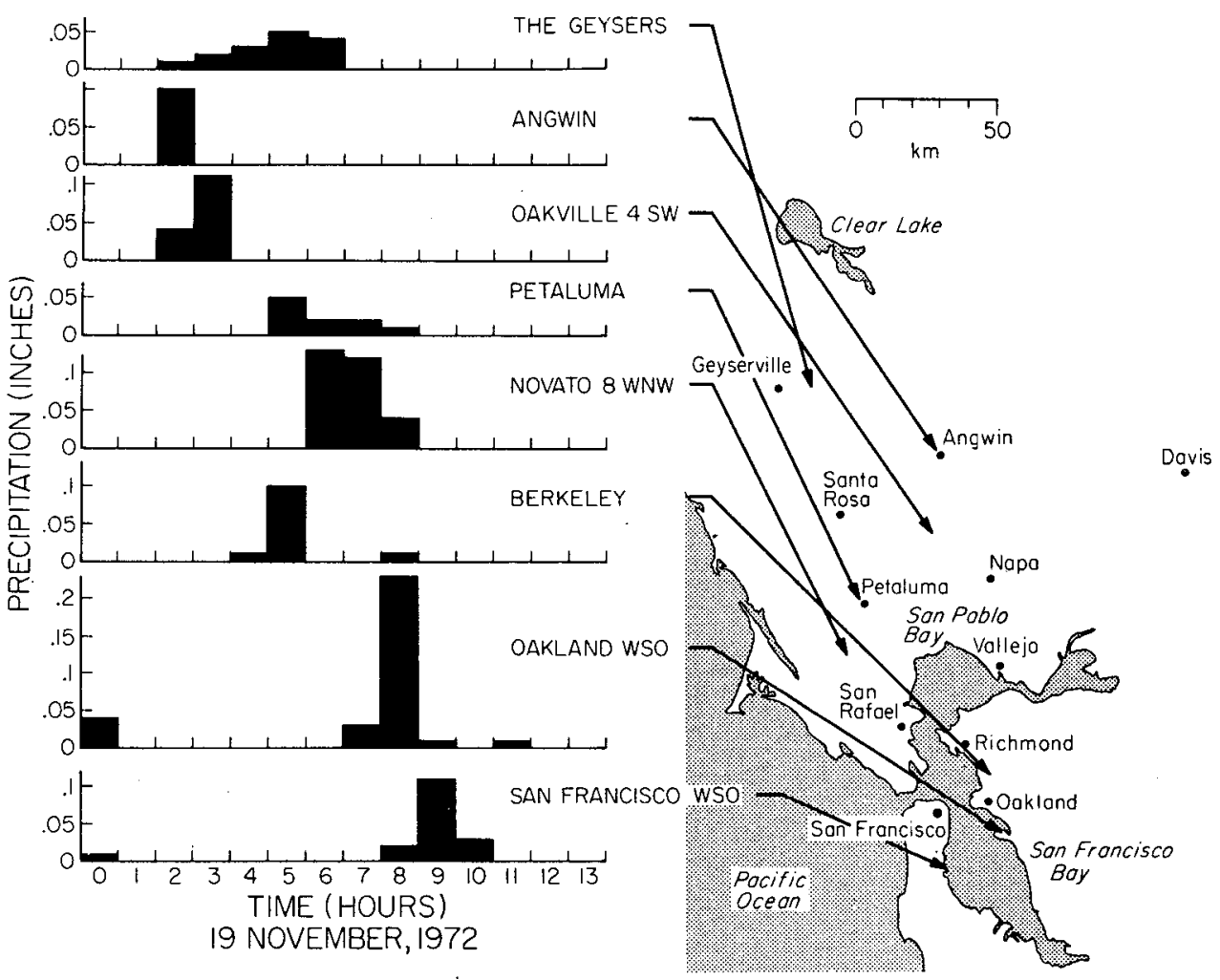

FIG. 13. Hourly rainfall data at eight stations in the Santa Rosa-San Francisco area just prior to and following the episode.

core of the downdraft might arrive at ground level in concentrations near those that exist in the layer aloft. In contrast, ozone entrained into a cloud whose top is well above the ozone layer would become diluted both by the ozone-free air in the core of the downdraft (brought down from above) and by that entrained from the environment between the ozone layer and the ground. From these observations we surmise that material transported from a layer aloft to the ground by a convective shower would produce the largest ground-level concentrations at about the time the top of the precipitating cloud entered the material layer.

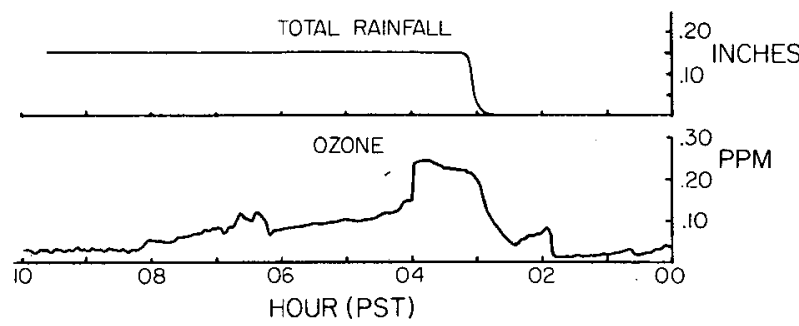

Fig. 14. Strip charts of the Santa Rosa oxidant recorder and the recording raingage at the Oakville 4 SW Site for 19 November 1972. The oxidant recording is the same as that shown in Fig. 2. The location of the Oakville raingage is indicated in Fig. 13.
We have already pointed out that the clouds that produced the showers with which the episode was associated appear to have first entered the layer of stratospheric air near Santa Rosa. South of this point the clouds pushed through the ozone layer and climbed to an altitude near $500 \mathrm{mb}$, as measured by radar in the vicinity of San Francisco. It is this growth of the precipitating clouds and the characteristics of the entrainment process described above that we believe are partly responsible for the absence of oxidant anomalies at sites outside of the Santa Rosa area. A second contributing factor is that by mixing the shallow layer of stratospheric air into the relatively deep layer of air below, the cumulus clouds erradicated the high concentrations of ozone aloft. Consequently, even if new cloud systems had formed south of Santa Rosa, by the time their tops had reached the level where the stratospheric air formerly existed, there would have been no ozone left to entrain. That the band of precipitating clouds did indeed alter the layer of air in which the stratospheric air resided is revealed in Fig. 15, which shows the potential vorticity and water vapor mixing ratio profiles approximately one hour after the episode. The corresponding profiles shown in Fig. 10 that were observed $11 \mathrm{~h}$ prior to the episode have been plotted in Fig. 15 for comparison. The amplitude of the potential vorticity 
maximum at $730 \mathrm{mb}$ was reduced considerably shortly after the episode, perhaps by latent heat releases associated with the band of clouds that produced the showers. The air at $730 \mathrm{mb}$ also has a slightly greater moisture content after the episode.

\section{Conclusion}

It has been shown that an intrusion of stratospheric air was responsible for five successive hours of oxidant concentrations in excess of the current NAAQS at Santa Rosa, Calif., on 19 November 1972. The highest of the five, hourly averaged values was $0.23 \mathrm{ppm}$. The certainty of this conclusion rests on evidence presented here both supporting this premise and contradicting hypotheses that other causes were responsible.

The set of events that led to this episode, namely, a high-level intrusion of stratospheric air, tapping of the intruded layer in the lower troposphere by convective shower clouds, and transport of the layer's constituents by a precipitation-induced downdraft into a stagnant air mass at the ground, is most likely to occur in association with frontal passages. In mountainous areas, where shallow layers of air of ten stagnate in valleys for many hours, the duration of episodes is potentially much longer than in open terrain.

Brief episodes of anomalous ozone concentrations similar to that described here have been reported by others. Attmannspacher and Hartmannsgruber (1973) reported that on seven different occasions in the winter of 1971, ozone anomalies of between 0.25 and $0.50 \mathrm{ppm}$ lasting for longer than $10 \mathrm{~min}$ were recorded on a $1000 \mathrm{~m}$ mountain peak in northern Germany. Each occurrence was during strong snow showers accompanying passing cold fronts. On three of these occasions balloons were launched shortly after the episode to measure ozone concentrations aloft. In all three cases a strong secondary ozone concentration was observed just above the tropopause. No thunderstorm activity was noted during any of these seven events and no large changes in the electric field strength were detected. Several cases were also observed in which ozone concentrations of 0.10 to $0.25 \mathrm{ppm}$ persisted for periods of an hour or more in the vicinity of thunderstorm downdrafts.

Davis (1973) reported ozone increases of 0.01 to $0.04 \mathrm{ppm}$ in thunderstorms over northern Florida during a 10-year period. In one instance the ozone recorder was off scale (concentration $>0.10 \mathrm{ppm}$ ) for a period of about $3 \mathrm{~h}$ during the passage of squall-line thunderstorms moving ahead of a cold front. It is not known whether the ozone observed in the vicinity of thunderstorms is produced by electrical discharges or whether it is entrained from the stratosphere, or whether both processes are active. Shlanta and Moore (1972) showed that the first mechanism is effective and Reiter and Mahlman (1965b) described a study
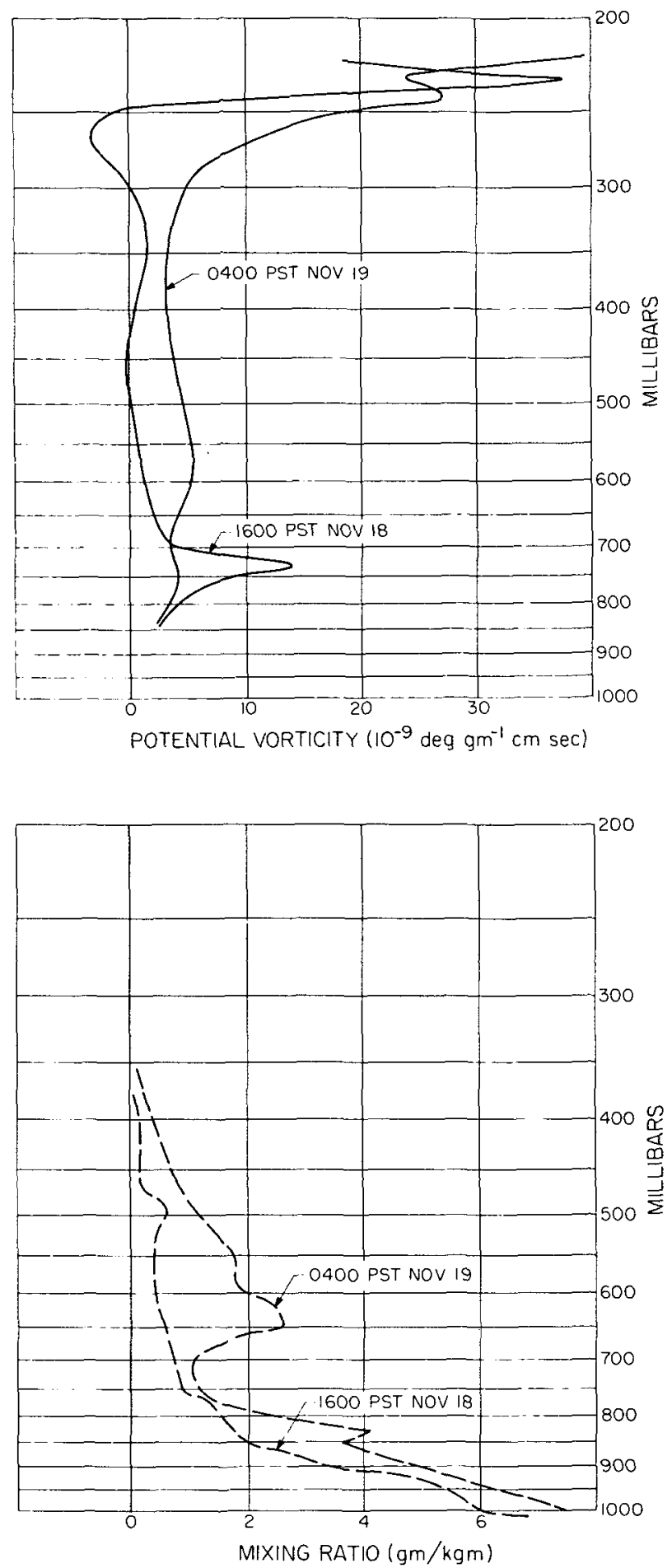

FIg. 15. Potential vorticity (a) and mixing ratio (b) profiles over Santa Rosa at 0400 PST 19 November 1972, approximately $1 \mathrm{~h}$ after the episode. The profiles for 1600 PST 18 November 1972, shown in Fig. 10, have been included for comparison.

in which a high reaching thunderstorm apparently entrained radioactive material from the stratosphere and deposited it at the ground in rainwater. Davis 
(1973) concluded that since ozone fluctuations were rarely observed during the thunderstorms of late summer and autumn (regardless of the lightning intensity) whereas fluctuations were frequent during the storms of late winter to earlier summer (when the tropopause is generally low), thunderstorm ozone is of stratospheric origin.

Chatfield and Harrison (1976) found a positive correlation between increases in ozone concentrations in the remote Olympic Mountains of Washington and the passage of cutoff lows originating in the Aleutian Island area. Although none of the ozone fluctuations observed by Chatfield and Harrison were as large as that reported here, it is interesting that the type of pressure systems that they associated with ozone increases is identical to that which we found responsible for the Santa Rosa episode (see Fig. 6).

That stratospheric ozone can reach the ground in concentrations that exceed the current National Ambient Air Quality Standard for ozone has obvious implications for the implementation of state and federal air quality standards. But before these standards can be modified to allow for stratospheric ozone effects, the magnitude of anomalous concentrations resulting from intrusions of stratospheric air and the frequency and location of occurrence of these intrusions must be established.

Acknowledgments. The author is greatly indebted to Dr. Charles Pyke of the Army Corp of Engineers for providing hourly rainfall data, Mr. James Goodridge of the California Department of Water Resources for providing strip charts from recording raingages in the Santa Rosa area, and Mr. James Sandberg of the Bay Area Air Pollution Control District for supplying meteorological and aerometric data as well as stripchart records of instruments at the Santa Rosa air monitoring station. The meteorological analyses were performed with the able assistance of Mr. Mike Borowski of the UCLA Department of Meteorology.

\section{REFERENCES}

Attmannspacher, W., and R. Hartmannsgruber, 1973: On extremely high values of ozone near the ground. Pure Appl. Geophys., 106-108, 1091-1096.

Byers, H. R., 1959: General Meteorology. McGraw-Hill, 540 pp. California Air Resources Board, 1972: California air quality data. Vol. 4, No. 4.
Chatfield, R., and H. Harrison, 1976: Ozone in the remote troposphere: Higher levels? Proc. Conf. on Ozone-Oxidants Interaction with the Total Environment, APCA, 77-83.

Danielsen, E. F., 1959: The laminar structure of the atmosphere and its relation to the concept of a troposphere. Arch. Meteor. Geophys. Biokl., A11, 293-332.

- 1961: Trajectories: Isobaric, isentropic and actual. $J$. Meteor., 18, 479-486.

_- 1968: Stratospheric-tropospheric exchange based on radioactivity, ozone and potential vorticity. J. Atmos. Sci., 25, 502-518.

- 1975: The natural stratosphere of 1974. CIAP Monogr., No. 1. A. J. Grobecker, Ed. DOT-TST-75-51. Climatic Impact Assessment Program, U. S. Department of Transportation, Washington, D. C., 115-122.

—, R. Bleck, J. Shedlovsky, A. Wartbug, P. Haagenson and W. Pollock, 1970: Observed distribution of radioactivity, ozone, and potential vorticity associated with tropopause folding. J. Geophys. Res., 75, 2353-2361.

Davis, D. R., 1973: Influence of thunderstorms on environmental ozone. Proc. Annual Tall Timber Fire Ecology Conf., 505-516.

Hecht, T. A., J. H. Seinfeld and M. C. Dodge, 1974: Further development of generalized kinetic mechanisms for photochemical smog. Environ. Sci. Tech., 8, 327.

Lamb, R. G., and M. Neiburger, 1971: An interim version of a generalized urban air pollution model. Atmos. Environ., 8, 563-596.

Mason, B. J., 1962 : Clouds, Rain and Rainmaking. Cambridge University Press, 145 pp.

Reed, R. J., 1955: A study of a characteristic type of upper level frontogenesis. J. Meteor., 12, 226-237.

Reiter, E. R., 1963: A case study of radioactive fallout. J. Appl. Meteor., 2, 691-705.

_-, 1966: Large scale atmospheric transport processes of radioactive debris. Atmos. Sci. Rep. No. C00-1340-8, Colorado State University, $54 \mathrm{pp}$.

$\longrightarrow$, and J. D. Mahlman, 1965a: Heavy radioactive fallout over the southern United States, November 1962. J. Geophys. Res., 70, 4501-4520.

- , and - 1965b: Heavy iodine-131 fallout over the midwestern United States, May 1962. Dept. of Atmos. Sci. Tech. Pap. No. 70, USAEC Rep. No. C00-1340-2, Colorado State University, 1-53.

Reynolds, S. D., P. M. Roth and J. H. Seinfeld, 1973: Mathematical modeling of photochemical air pollution. Atmos. Environ., 7, 1033-1061.

Scott Research Laboratories, 1970: 1969 atmospheric reaction studies in the Los Angeles basin, Vol. III: El Monte ground data. NAPCA No. 70-6, Plumsteadville, $\mathrm{Pa}$.

Shlanta, A., and C. D. Moore, 1972: Ozone and point discharge measurements under thunder clouds. J. Geophys. Res., 77, $4500-4510$.

Staley, D. O., 1960: Evaluation of potential vorticity changes near the tropopause and the related vertical motions, vertical advection of vorticity, and transfer of radioactive debris from stratosphere to troposphere. J. Meteor., 17, 591-620. 